\title{
Propositions de la Commission de l'Union européenne
}

Le 30 novembre 2016, la Commission européenne a rendu publique une proposition de réforme des marchés de l'énergie intitulée Clean Energy for all Europeans, plus connue sous l'appellation de Winter Package. La chaire Économie du Climat de l'université Paris-Dauphine et de Montpellier a publié en février 2017 une analyse de ce document de 5000 pages sous le titre «Le Winter Package : quelles ambitions pour quelle cohérence?», qui étudie les principales questions suivantes :

- remettre le consommateur au centre des politiques;

- renforcer la gouvernance des réseaux et des marchés;

- améliorer l'intégration des renouvelables;

- la question de la tarification de l'électricité;

- le rôle central du prix du carbone.

Nous publions ce document en annexe 2 avec l'aimable autorisation des auteurs. 
